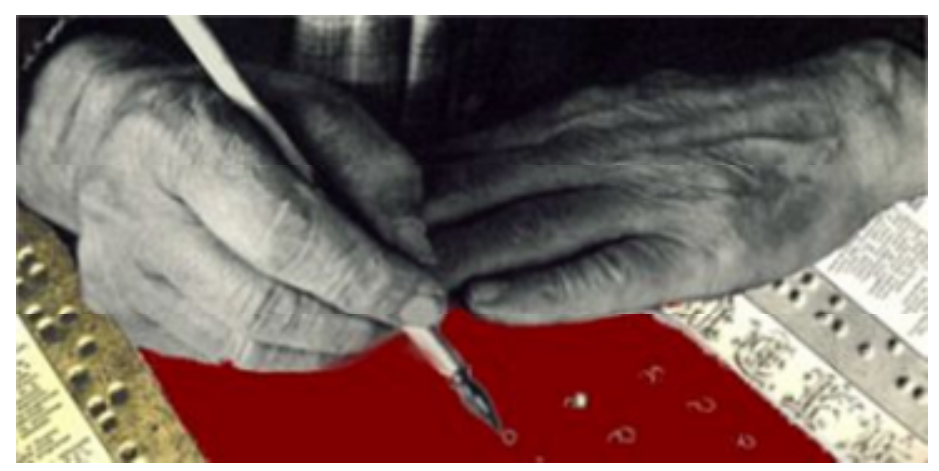

Colagem digital Conceição Bicalho

\title{
Leitura e democracia: \\ bibliotecas comunitárias e ensino de Língua Portuguesa escrita
}

\begin{abstract}
Jairo Rodrigues
Maria Antonieta Pereira

Jairo Rodrigues - Mestre em Estudos Literários pela Faculdade de Letras da UFMG. Coordena, desde janeiro de 2005, o projeto Bibliotecas Comunitárias Auto-geridas do Programa de Ensino, Pesquisa e Extensão A tela e o texto.

Maria Antonieta Pereira - Professora de Teoria da Literatura e Literatura Comparada na Faculdade de Letras da UFMG. Desde 1998, coordena o Programa de Ensino, Pesquisa e Extensão A tela e o texto. Autora de livros e artigos, publicados no Brasil e no exterior, sobre teorias de leitura e experiências de formação de leitores.
\end{abstract}

\section{Resumo}

Análise da implantação de bibliotecas comunitárias como um estímulo à leitura e ao protagonismo dos agentes envolvidos no processo contrapondo-se à pratica nacionalmente institucionalizada de que $O$ acesso à leitura e aos bens culturais seja direito exclusivo das elites.

Palavras-chave: leitura, bibliotecas comunitárias, alfabetização. 


\section{I - As bibliotecas comunitárias}

Os motivos que geram os baixos índices de leitura dos brasileiros são diversos e complexos, podendo ser identificados na ineficiência do processo de formação do leitor, na falta de estimulo à leitura, no descompasso entre oferta e procura de material para leitura, no baixo número de bibliotecas. Segundo dados do Sindicado Nacional dos Editores de Livros (SNEL), o número de bibliotecas públicas no país gira em torno de 5000. Em se tratando de bibliotecas escolares, são 40.000 espalhadas pelo território nacional.(1) Esses números, quando aproximados à população nacional, de aproximadamente 190 milhões de habitantes, demonstram a necessidade de ampliação dos espaços de leitura, principalmente para aqueles que já não se encontram em processo escolar e que, portanto, não têm mais acesso a exercícios regulares de leitura. Ao se findar o vínculo escolar, para a imensa maioria da população brasileira é vetado o direito ao livro e à biblioteca. Nesse caso, uma política de inclusão urge atender, sobretudo, às camadas sociais que vivem nas margens das grandes cidades e no interior do país, já que, em geral, as bibliotecas públicas estão localizadas em regiões centrais das cidades. Nesse contexto, uma proposta que tem ganhado corpo junto às comunidades periféricas relaciona-se à criação de bibliotecas comunitárias. Esse processo, no entanto, não é tarefa facilmente realizável. Para ampliar a discussão a respeito do tema, narraremos a seguir uma experiência pessoal que contribui para se refletir sobre o estímulo à leitura e à criação de bibliotecas.

\section{Depoimento de Jairo Rodrigues}

Ao pensar sobre a ementa Por que eles não lêem? deparei-me com outro questionamento: como a leitura entrou em minha vida? Dentre as diversas cenas que me vieram à mente, uma destacou-se pela nitidez das imagens e sensações rememoradas: um certo cheiro de passado, um ambiente tranqüilo e silencioso onde tesouros eram encontrados todas as sextas-feiras por mim e meus colegas de turma, durante o primeiro ano do primário, hoje chamado de "ensino básico". Eram as aulas de "biblioteca" (nome dado às aulas que aconteciam naquele local). Além de vasculhar as prateleiras atrás de livros cujas histórias nem sempre conseguíamos ler, mas que estampavam imagens belíssimas, coloridas, tínhamos as "aulas" de piano, quando a turma, em fila, se revezava, aluno por aluno, para tocar uma única tecla. Voltávamos ansiosos ao fim da fila para aguardarmos a próxima nota. Também era nessas aulas que ouvíamos as histórias infantis por meio de um gravador e víamos, maravilhados, cenas da história narrada sendo projetadas em slides na parede da biblioteca que era para nós, alunos do primário da Escola Estadual Artur Joviano, um espaço de descoberta não só da leitura em sua forma escrita, mas também manifestada em imagens e sons. Hoje, depois de mais de vinte anos, integro o Projeto Bibliotecas Comunitárias Auto-geridas do Programa de Ensino, Pesquisa e Extensão A tela e o texto. Assim como o Programa, o Projeto tem por objetivos principais elevar os níveis de leitura da população brasileira e, para tanto, buscamos por meio de incentivo, assessoramento e acompanhamento, promover, em ações conjuntas 
com a comunidade, a criação de bibliotecas em regiões cujo acesso à leitura seja deficitário.

A proposta de criação da primeira biblioteca comunitária surgiu no segundo semestre de 2004 durante o curso "Leitura de telas e textos" ministrado pelo Programa A tela e o texto, no CAC Barreiro (2). No decorrer das aulas, os alunos (portadores de sofrimento psíquico, egressos de hospital psiquiátrico e assistidos pelo Centro de Convivência do CAC) demonstraram a necessidade de se instituir um espaço de leitura para uso da comunidade e deles próprios.

O processo de implantação dessa biblioteca demandou uma série de reuniões que envolveram representantes do CAC, de outras bibliotecas da região e do Programa $A$ tela e o texto. Nesses encontros foram discutidos aspectos mais gerais, como a democratização da leitura, e aspectos práticos, como a aquisição do acervo (via doações), o local de funcionamento de uma sala de leitura e os plantões de voluntários para atendimento ao público. Atualmente, O CAC Barreiro já instalou sua sala de leitura e construiu um acervo satisfatório. Contudo, ainda não transformou esse espaço num lugar efetivo de leitura, porque não conseguiu organizar um atendimento constante ao público-leitor da região.

A partir da experiência do Barreiro, o projeto desdobrou-se para outros locais de Belo Horizonte e da Região Metropolitana. Hoje, acompanhamos duas bibliotecas em fase de implantação: uma no bairro São Paulo, em parceria com o CAC da região, e outra na Quinta do Sumidouro (3), em ação conjunta com a comunidade local. Além dessas, o Programa A tela e o texto assessora a dinamização do funcionamento da biblioteca do CAC Providência, em Belo Horizonte, e da Escola Estadual da Lapinha, município de Lagoa Santa.

Escolhemos, dentre as experiências acima relatadas, abordar o processo de criação da Biblioteca Comunitária da Quinta do Sumidouro, pois sua implantação ocorreu de forma bastante diferente dos outros casos, já que não contamos com apoio institucional. Ou seja, a idéia de se criar a biblioteca comunitária surgiu e se desenvolveu durante reuniões entre moradores e lideranças das comunidades de Quinta do Sumidouro, Lapinha e Fidalgo. O objetivo dessas reuniões era discutir e organizar meios para se melhorar o acesso das populações locais aos bens culturais que circulam no país, especialmente os livros.

No caso de Quinta do Sumidouro, após decidirem montar a biblioteca, os moradores iniciaram uma série de encontros acompanhados pela professora Maria Antonieta Pereira, para estabelecer os mecanismos de seu funcionamento. Para abrigar o 
acervo, oriundo majoritariamente de doações, foi ocupada uma sala da Casa Fernão Dias, na praça central da Quinta do Sumidouro. Gláucia Mendes, sub-coordenadora do Projeto, ministrou um mini-curso sobre catalogação e organização da biblioteca para os moradores envolvidos em sua criação. Constituiu-se uma primeira diretoria e, em 25 de junho de 2005, uma grande festa popular organizada pelos moradores marcou a inauguração da Biblioteca Comunitária da Quinta do Sumidouro.

Constituir a biblioteca e inaugurá-la, contudo, não foi suficiente para garantir seu funcionamento, pois os responsáveis pela continuidade do processo não se envolveram nele de forma decisiva. Passamos, então, a nos reunir quinzenalmente com os integrantes da biblioteca, assessorando suas ações e monitorando a realização das mesmas. Durante esse período, a equipe que compunha a diretoria se alterou diversas vezes. Muitos moradores da Quinta do Sumidouro entraram e saíram do projeto, o acervo esteve durante alguns meses sem cuidados e catalogação, os plantões para empréstimo funcionavam de forma precária.

Aos poucos, contudo, o grupo foi acreditando em sua capacidade de organização e de domínio das tecnologias intelectuais (4) necessárias para se gerir uma biblioteca comunitária. Após certa aprendizagem de auto-estima e cidadania, o estatuto e o regimento da biblioteca foram lavrados em cartório e o grupo descobriu formas de atender às necessidades básicas de manutenção dos serviços de catalogação, empréstimo e controle dos livros, por meio de rifas, festas beneficentes etc. Cabe ressaltar, contudo, que o auto-reconhecimento do grupo como uma equipe de trabalho que buscava a auto-gestão (5) foi expresso e concretizado pela organização e pelo cumprimento dos plantões de atendimento ao público. A partir do momento em que o grupo conseguiu - de forma planejada, regular e consensual - oferecer um atendimento ao público, ele foi também capaz de ultrapassar as relações primárias que 0 impediam de atuar livremente. As projeções de fantasmas familiares (que, grosso modo, poderiam ser resumidas nas relações entre autoritarismo dos pais/dependência dos filhos), as sensações de impotência, o medo do protagonismo e de suas respectivas atitudes de liberdade/responsabilidade foram obstáculos pouco a pouco vencidos. A necessidade de atender aos estudantes carentes de informação, a urgência de proteger os livros das goteiras, do mofo e do roubo, o desejo de manejar os códigos culturais até então considerados uma posse exclusiva das elites cultas foram assuntos longamente discutidos e finalmente assumidos pelos responsáveis pela Biblioteca da Quinta. 
o grupo encontrou sua saída fora/dentro dele mesmo - ao invés de olhar, narcisicamente, para o fundo do poço de seu próprio umbigo e se afogar nesse beco sem saída, ele estabeleceu sua finalidade fora de si mesmo, buscando auto-definir-se em função das necessidades de toda uma população que dele necessitava. Essa foi sua opção enquanto grupo auto-gestor. Movendo-se para fora, definindo atribuições em função de demandas externas, olhado para a frente, dimensionando seu perfil a partir de necessidades concretas, o grupo caminhou, cresceu, acreditou em si, organizou-se, buscou saídas, tornouse independente de um pai, de uma mãe, de prefeitos, vereadores e compadres. O Programa A tela e o texto ainda está por lá, assessorando, mas quem decide tudo é a equipe, quem mantém o dia-a-dia da biblioteca em funcionamento é uma motivação grupal. Com reconhecimento e apoio da comunidade.

A experiência de implantação da Biblioteca Comunitária da Quinta do Sumidouro nos possibilitou desenvolver reflexões que se mostraram relevantes para o aprimoramento de nossas ações. o ato de estimular a leitura, como o faziam as professoras da Escola Estadual Artur Joviano, é fundamental no que se refere à criação de uma biblioteca comunitária, mas outros elementos também devem ser inseridos nesse processo. Não basta que a comunidade tenha interesse pela implantação de uma biblioteca, ela deve se apropriar da idéia e da instituição criada; noutras palavras, a biblioteca pertence à comunidade, só assim merecerá ser chamada de "comunitária". Isso está totalmente dependente da construção de autonomia por parte da equipe responsável pela biblioteca, principalmente no que se refere às suas ações e tarefas visando ao funcionamento cotidiano do espaço.

Parece incoerente falarmos de autonomia quando afirmamos que a biblioteca da Quinta ainda carece de acompanhamento. Contudo, para que um grupo seja autônomo, ele necessita conhecer certas ferramentas não só de trabalho grupal, mas também de atuação técnica. O grupo tem que desenvolver habilidades para desenvolver ações que, apesar de simples, são complicadas para iniciantes. Um dos exemplos disso é a catalogação dos livros cujo processo, com base na codificação das áreas do conhecimento, apóia-se em tabelas extensas e implica a identificação de cada campo ou subcampo do saber. Essa tarefa mostrou-se extremamente difícil de ser executada por professores e estudantes sem formação na área de Ciência da Informação. O mini-curso oferecido pelo Programa A tela e o texto tinha sido insuficiente para que o processo fosse totalmente assimilado pelos integrantes da biblioteca. Para que a catalogação fosse efetivada, foi necessário que a coordenação do projeto propusesse um mutirão, durante todo um fim de semana, cujos integrantes foram adequando a tabela classificatória à realidade de seu conhecimento e de seu 
acervo. A identificação e a listagem dos livros para um controle mínimo do acervo, a confeç̧ão de fichas de empréstimo e tarefas afins foram sendo paulatinamente compreendidas e desenvolvidas pelo grupo. Os encontros regulares acabaram por estabelecer uma rotina, a partir da qual o grupo tem construído sua autonomia, buscando soluções e compreendendo que a biblioteca está sob sua responsabilidade, mas pertence à comunidade.

Sendo assim, ao retornarmos à pergunta Por que eles não lêem? constatamos que uma das causas da não-leitura é a própria insuficiência de bibliotecas, para atender à demanda reprimida de leitura das periferias. Evidentemente, não basta criar bibliotecas, é preciso que os cidadãos locais saibam que poderão usá-la, que o direito de ler também lhes pertence.

\section{Depoimento de Maria Antonieta}

Minha primeira experiência com os livros é intra-uterina. Durante a gravidez, minha mãe leu o romance Maria Antonieta, de Alexandre Dumas, e ficou muito abalada com o destino da jovem mulher. Em homenagem a ela, deume o mesmo nome. Esse fato me despertou para a leitura muito cedo. É como se eu já tivesse nascido sabendo ler. Sou incapaz de lembrar do tempo em que ainda não lia. Esse fato também me revelou a ambigüidade do mundo: se meu nome é resultado de uma postura feminista anterior ao feminismo (reabilitação da mulher decapitada), também é fruto de uma atitude antiburguesa (repulsa pela violência do patíbulo) e romântica (sacralização da heroína, saudade do passado histórico). Na minha infância, havia alguns livros em casa. Um deles, de Biologia, era terminantemente proibido para as crianças porque trazia imagens nuas de um homem e uma mulher. Freqüentemente lido às escondidas, suas páginas centrais eram transparentes e superpostas: os ossos, os músculos, os sistemas nervoso e sangüíneo... A gente ia folheando, superpondo, decompondo os corpos. Havia também Navio negreiro, de Castro Alves, e Sargento Nikola, de Istvan Tamás. Meu pai nos trazia livros da Biblioteca da Prefeitura e, como não era professor, deunos a ler ainda em tenra idade A República, de Platão, e uma coleção fartamente ilustrada sobre a Segunda Guerra Mundial. Na Escola Estadual Romero Carvalho, havia uma biblioteca de verdade. Monteiro Lobato. Anderson. Perrault. Grimm. O patinho feio. A bonequinha preta. O visconde. A filha do rei do pântano. A imagem de uma rainha belíssima e feroz, com o bastão em riste para matar o sapo que, todos sabem, era o príncipe disfarçado. Esse lugar extraordinário foi transformado em laboratório pela diretora da escola(6). As crianças de hoje já não podem sonhar. Sua realidade é dura, desumana. Não nos surpreendamos se na vida adulta se tornarem ferozes. Lobato está encurralado numa caixa poeirenta. Grimm foi destruído. A rainha matou o sapo. As crianças de hoje já não podem fabular. Dessa pobreza cultural padece a maioria absoluta dos brasileiros.

A biblioteca da Quinta do Sumidouro nasceu, em parte, por tudo que Jairo Rodrigues já relatou. E, em parte, porque nós, os brasileiros que somos leitores, sabemos que os bens culturais do país precisam ser compartilhados. Se fôssemos escrever a História da Leitura no Brasil, teríamos que começar pela exclusão cultural sofrida por milhões de escravos índios e africanos. Durante séculos, foi negado a essa população o mero e simples direito de ler. A interdição da leitura tem sido uma 
das formas mais eficazes de nossa elite dirigente manter sua posição de comando, porque assim se sobrepõe ao "povão" inculto ou se distancia do "povinho" ignorante. O atraso dessa mentalidade foi se estratificando no país por meio de mecanismos que justificavam sua perpetuação. Dentre eles, o mais eficiente é a naturalização de altos índices de analfabetismo associados à baixa oferta de livros. A violência da escravidão (não ser dono de si mesmo) legitimou muitas formas de violência cultural (inclusive a de não ter direito ao livro). Milhões de analfabetos. Milhões de analfabetos funcionais. Milhões de não-leitores (7). Livros caros. Livros preparados como objetos de luxo para quem pode comprá-los. Pobres, índios, negros, mestiços e mulheres têm sido condenados a uma civilização ágrafa, mantida pela oralidade e sustentada por baixos níveis de informação (8). E tudo isso foi transformado em algo natural. Como se o mundo devesse ser sempre assim. Mulher no tanque. Negro na favela. Índio no cerrado.

Embora esses mecanismos de exclusão tenham sido sempre questionados por intelectuais e movimentos comprometidos com os processos de democratização da cultura (9), só mais recentemente a pressão social foi capaz de forçar o surgimento de políticas públicas dedicadas à erradicação do analfabetismo, aos investimentos no letramento e à disseminação de livros pelo menos no âmbito escolar. Vários Programas do Governo Federal (Brasil Alfabetizado, Pró-Jovem, Educação de Jovens e Adultos, PNBE) ou de instâncias estaduais e municipais apostam na superação dos atuais níveis de exclusão cultural, que passa a ser vista como uma violência. A população brasileira está despertando para a realidade do analfabetismo e da não-leitura. Esse tipo de exclusão passa a ser uma anomalia social deixando, portanto, de ser algo natural e aceitável. Felizmente, cada vez mais, há perspectivas que estranham e des-naturalizam tais mecanismos de dominação.

Muitos de nossos problemas de leitura só são percebidos quando contemplamos o país com esse olhar estrangeiro. Pessoalmente, vivi essa experiência de forma aguda. Em 2003, quando morei em Buenos Aires fazendo uma pesquisa de Pós-doutorado, deslocavame sempre de metrô. Em cada vagão, havia em torno de 10 pessoas lendo livros e outros tantos lendo jornais e revistas (10). Nunca fui a Cuba, mas sei que sua população é grande leitora. Em outros países latino-americanos, como Uruguai e Chile, os níveis de leitura também são superiores aos nossos. E mesmo no Peru e no Paraguai, que enfrentam níveis mais baixos de letramento - contudo, sempre superiores aos do Brasil - é possível encontrar não só livros mais baratos que os nossos, mas também uma grande quantidade de sebos (11) que atendem às populações mais pobres, aos estudantes de nível 
médio, aos aposentados e desempregados. A América Espanhola lê mais - e melhor - que a América Portuguesa, se considerarmos o conjunto da sociedade e não somente os estratos cultos da população.

Noutras palavras, ainda estamos pagando o ônus da escravidão. As sequielas de uma sociedade culturalmente injusta estão visiveis por todo lado, mas muitos educadores foram socialmente treinados para não vê-las. Esse treinamento para a cegueira pedagógica pode ser configurado em currículos que dificilmente abordam alguns dos principais problemas educacionais do país. No caso específico do analfabetismo, ele não deveria ser um importante motivador de ações de pesquisa, ensino e extensão dos cursos de Letras, Pedagogia, Psicologia, Ciências Sociais, Ciências Políticas, Medicina, Fonoaudiologia etc.? Numa sociedade com níveis mais elevados de compreensão da cidadania, os baixos níveis de leitura da população brasileira não deveriam ser objeto de investigação cuidadosa e crítica? Não seria o caso de rompermos com uma história nacional de passividade diante da indiferença ou da incompetência do Estado, no que tange às políticas públicas de leitura?

No caso específico dos cursos de Letras, a regra geral é a ausência desse debate público e crítico. Evitamos a questão da não-leitura nacional como se ela fosse algo menos importante. Ignoramos as dificuldades de formação de leitores numa sociedade cujos livros são muito caros e cuja tradição de nãoleitura é secular. Ainda pensamos nos processos de leitura/escrita como um problema da área de Língua Portuguesa e Literatura Brasileira: como se as outras disciplinas não utilizassem textos para produzirem conhecimento, como se a maioria absoluta do conhecimento científico produzido no Brasil não tivesse como suporte o uso da Língua Portuguesa escrita. Necessitamos de revisores para os trabalhos finais de Pós-Graduação em Letras, quando seus autores deveriam ser formados como especialistas em leitura e escrita, ou seja, com a competência de revisores. Muitas vezes, a crítica de uma visão purista da gramática normativa da Língua Portuguesa foi realizada de forma inadequada, levando os futuros professores da área a desprezarem o domínio das regras básicas de construção textual. Noutras vezes, o estudo da oralidade e das variações lingüísticas levou a uma crítica tão equivocada dos padrões gramaticais da língua escrita que se obteve um leitor/redator inseguro ou indiferente quanto ao uso dos mesmos. Em sua grande maioria, os professores de Ensino Fundamental e Médio que formamos não conseguem expressar-se de forma satisfatória em Língua Portuguesa escrita, o que aponta para suas dificuldades também no processamento da leitura porque, embora estes sejam processos com percursos próprios, eles têm alto nível de interdependência. 
Sem dúvida, a crítica ao gramaticalismo foi feita na melhor das intenções. Presenciei seus pontos altos e participei ativamente dela, como estudante de Graduação. Talvez seu resultado mais significativo esteja na conquista de uma visão mais aberta e democrática, por parte dos professores, do uso da língua materna. Contudo, essa perspectiva foi mal conduzida e/ou interpretada por amplas camadas de educadores que, desprezando os padrões da língua escrita, tornaram-se incapazes de utilizá-los e, portanto, de ensiná-los a seus jovens alunos. Essa atitude contribui para reforçar a tragédia nacional de milhões de analfabetos funcionais. Diante dessa realidade, algumas perguntas precisam ser reformuladas: se é verdade que há uma imensa variação lingüística no Brasil como em qualquer agrupamento humano - isso significa que devemos criar infinitos padrões de língua escrita? E antes que a pergunta pareça um despropósito, é preciso complementá-la: não é isso que induzimos, ao formar professores de Língua Portuguesa que não dominam o padrão escrito? Não é isso que propomos, ao criticar severamente a gramática normativa da língua escrita diante de alunos que dominam pouco tais regras e passam a desprezá-las antes de conhecê-las e, por isso mesmo, jamais irão se aventurar em tais conhecimentos?

É verdade que nosso padrão de língua escrita está, em muitos aspectos, distante da língua efetivamente falada no Brasil. Mas justamente porque se trata de um recurso comunicacional que pressupõe a ausência de interlocutores face a face - e, dentre outros problemas, prejudica o esclarecimento de mal entendidos, a ampliação de descobertas, o avanço na interlocução crítica - a língua escrita precisa de normas claras que sejam seguidas por todos. Caso contrário, se cada um criar seu próprio padrão de escrita, esse "padrão" deixa justamente de ser padrão - de ser uma norma geral - e a comunicação fica prejudicada. Noutras palavras, se nosso padrão não corresponde à realidade, temos que modificá-lo. Mas qual seria a estratégia mais produtiva para o falante/redator/leitor de Língua Portuguesa do Brasil: desprezar o padrão e tornar-se incompetente em seu uso, a partir de estratégias individuais? Questionar o padrão, mas conhecê-lo bem, de forma a ser capaz de adequá-lo à Língua Portuguesa do Brasil? Criticar o padrão e lutar para que ele sofra modificações, a partir de estratégias nacionais, coletivas, legais e articuladas com um mínimo de consenso?

Algumas contradições muito evidentes nessa problemática podem ser verificadas nos seguintes casos: a) o professor não ensina a seus alunos o uso da gramática normativa da Língua Portuguesa (ocupado que está em criticá-la), mas ele próprio a usa na escrita de seus artigos literários e científicos; b) a crítica da gramática normativa, que tem como objetivo suscitar uma visão mais aberta de uso da língua e promover níveis mais 
elevados de inclusão cultural, muitas vezes produz exatamente - efeito contrário, consolidando a exclusão de setores já segregados relativamente à cultura letrada. O exemplo mais claro dessas contradições pode ser encontrado nos processos de seleção para estudo e emprego, em que se usa o padrão culto da língua: quem o domina é aprovado; os demais permanecem desempregados, subempregados, excluídos das universidades públicas e gratuitas (que acolhem os que tiveram acesso à cultura letrada em seus vários níveis, desde a escola fundamental e, paradoxalmente, podem pagar um curso superior).

Os problemas até aqui abordados certamente não constituem novidade para os educadores habituados a pensar suas tarefas em contextos mais amplos, para além de uma estrutura disciplinar e local. Contudo, essa discussão ainda é necessária em amplos extratos sociais, especialmente naqueles afastados dos grandes centros e das universidades. Essa reflexão precisa ultrapassar os limites da mesa-redonda, do gabinete de trabalho, do grupo restrito de pesquisadores (12). A tentativa de responder à pergunta por que eles não lêem? pode nos levar a diferentes abordagens da formação de leitores. Contudo, no Brasil contemporâneo, algumas das respostas a essa questão passam pela necessidade de difusão do livro (objeto fundamental da leitura) e pela capacitação de professores e estudantes no uso da Língua Portuguesa escrita (sujeitos fundamentais desse processo). Contudo, diante de problema tão complexo, outras medidas serão necessárias. Precisamos construí-las.

\section{Resumen}

Análisis de la implantación de bibliotecas comunitarias como un estímulo a la lectura y al protagonismo de los agentes involucrados en el proceso, contraponiéndose a la práctica nacionalmente institucionalizada de que el acceso a la lectura y a los bienes culturales sea derecho exclusivo de las elites.

Palabras-clave: lectura, bibliotecas comunitarias, alfabetización.

\section{Notas}

(1) http://www.snel.org.br/noticias/jornal30.htm

(acessado em 02 de novembro de 2006).

(2) CAC é a abreviatura de Centro de Apoio Comunitário - espaços mantidos pela Prefeitura Municipal de Belo Horizonte que prestam assistência social e cultural às comunidades periféricas.

(3) Quinta do Sumidouro é um distrito do município de Pedro Leopoldo que, embora situado numa zona considerada rural, já se encontra fortemente inserido nas problemáticas urbanas. O nome do local advém de questões histórias e geográficas. Tendo sido a quinta povoação fundada pelo 
bandeirante Fernão Dias, e contando com grutas rochosas (ou sumidouros) por onde suas águas naturais desaparecem e passam a correr subterraneamente, o local passou a se chamar Quinta do Sumidouro.

(4) O conceito de "tecnologias intelectuais", proposto por Pierre Lèvy, apresenta uma inextricável articulação entre técnica, política e projetos culturais, em que um novo campo de forças (aberto, conflituoso e parcialmente indeterminado) se apresenta. Ao invés de uma nova "crítica filosófica da técnica", o autor discute "a possibilidade prática de uma tecnodemocracia, que somente poderá ser inventada na prática". Segundo ele, "a filosofia política não pode mais ignorar a ciência e a técnica. Não somente a técnica é uma questão política, mas é ainda, e como um todo, uma micropolítica em atos, como veremos em detalhes no caso das interfaces informáticas". Cf. LÈVY, op. cit. p. 9-10.

(5) O aprendizado do trabalho em grupo é muito importante para o desenvolvimento de projetos comunitários, já que eles dependem, fundamentalmente, das leis de funcionamento criadas pelo próprio grupo, seja em sua relação interna, seja na interação com a comunidade. Durante a implantação da Biblioteca de Quinta do Sumidouro, estávamos bastante interessados no conceito de "grupo operativo", de Pichon-Rivière, segundo o qual uma estrutura de equipe só se forma na medida em que ela opera. Noutras palavras, o grupo se constitui pelas ações que desenvolve (pela adoção de um projeto comum) e pela capacidade de analisar a si mesmo enquanto realizador de tais ações. Cf. PICHON-RIVIÈRE, 1998.

(6) A biblioteca da Escola Estadual Romero Carvalho atendia à população de Sumidouro (hoje, Fidalgo) e de Quinta do Sumidouro, duas localidades que formam um só Distrito, pertencente ao Município de Pedro Leopoldo.

(7) Se considerarmos apenas a população infanto-juvenil do Brasil, ainda temos 1,3 milhão de crianças e adolescentes entre 10 e 17 anos que trabalham, ao invés de estudar, 4 milhões de crianças entre 4 e 14 anos que estão fora da escola e $800 \mathrm{mil}$ crianças em idade escolar obrigatória também fora da escola. Cf. CURY, C. R. J. Cadernos de Pesquisa, v. 35, n. 124, p. 11-32, jan./abr. 2005 .

(8) Isso não ofereceria maiores problemas se não estivéssemos, há séculos, num modelo de sociedade baseada na escrita e mais recentemente na revolução cibernética, que depende do padrão alfabético. Segundo Lèvy, historicamente pode-se registrar três tipos de sociedade - a da oralidade primária (sem escrita), a da oralidade secundária (com escrita) e a da virtualidade. Embora na atualidade a sociedade canônica seja virtual, ela não existe sem a escrita. Sem alfabetização - e, portanto, sem leitura e sem leitores não é possível dominar a informática. Cf. LÈVY, Pierre. op.cit.

(9) Ao longo de nossa História, inúmeros pensadores dedicaram-se à reflexão sobre os problemas culturais do Brasil. Paulo Freire constitui um ícone dessa busca já que nos deu as mais avançadas teorias de leitura, utilizadas hoje pelo mundo inteiro, especialmente em projetos de grande monta como os da UNESCO. Contudo, suas propostas são ignoradas por grande parte dos educadores e dos órgãos encarregados das políticas públicas de leitura.

(10) Nessa pesquisa, em que investiguei a formação de auto-imagens de argentinos e brasileiros, pude comparar as histórias da formação de leitores em ambos os países. Constatei que, ao final do século XIX, enquanto, na Argentina, Sarmiento investia maciçamente na educação popular tentando superar os $80 \%$ de analfabetismo do país, no Brasil, D. Pedro II assinava as leis do Ventre Livre e dos Sexagenários. Esses fatos mostram como a escravidão imposta por uma parte da população à outra impedia a constituição da nacionalidade brasileira, inclusive em termos de políticas 
culturais que beneficiassem o conjunto da sociedade. Quando a Argentina apostava numa proposta de democracia cultural, explicitando claramente o desejo de construir uma nação cujos indivíduos compartilhassem os bens advindos da alta cultura européia, o Brasil instalava as primeiras condições para coibir a posse de uma multidão de escravos analfabetos por parte da minoria letrada. Ou seja, se uns já tinham obtido relativo consenso em torno de um projeto burguês de nação, outros ainda estavam lutando contra formas pré-capitalistas de organização da sociedade.

(11) Sendo uma livraria que atende diretamente ao leitor de baixa renda, o sebo é um dos mais importantes mecanismos de acesso ao livro. A esse respeito, $v$. neste número da Revista txt uma entrevista com o Sr. Amadeu, dono do sebo mais antigo de Belo Horizonte.

(12) A universidade do século XXI talvez precise recuperar a função que teve, nos anos $60 / 80$ do século XX, quando atuou de fato como um fórum de debates dos grandes problemas nacionais. Cf. SOUSA SANTOS, 2004.

\section{Bibliografia}

CURY, C. R. J. Cadernos de Pesquisa, v. 35, n. 124, p. 11-32, jan./abr. 2005 .

ENRIQUEZ, Eugène. O vínculo grupal. In: MATA MACHADO, Marília N. et al (org.). Psicossociologia - análise social e intervenção. Belo Horizonte: autêntica, 2001 .

LÈVY, Pierre. As tecnologias da inteligência: o futuro do pensamento na era da informática. Trad. C. I. da Costa. Rio de Janeiro: Ed. 34, 1993.

PICHON-RIVIÈRE. Enrique. Teoria do vínculo. São Paulo: Martins Fontes, 1998 .

SOUSA SANTOS, Boaventura de. A universidade no século XXI. São Paulo: Cortez, 2004 .

PEREIRA, Maria Antonieta. Subdesenvolvimento, auto-imagem e exclusão no Brasil e na Argentina. Pesquisa de Pós-doutorado desenvolvida na Universidad de Buenos Aires, em 2003 (bolsa CAPES/SECYT).

PEREIRA, Maria Antonieta. Jogos de linguagem, redes de sentido: leituras literárias. In: Anais de O jogo do livro, CEALE/FAE/UFMG, 2006. (no prelo)

PEREIRA, Maria Antonieta. A FALE/UFMG na formação de leitores e de políticas públicas de inclusão cultural. VI SEVFALE, 2006.

PEREIRA, Maria Antonieta. Enfoques y estrategias para la enseñanza de literatura. Conferência, a convite da embaixada do Brasil, no Congresso de Língua e Literatura da Universidad Metropolitana de Ciencias de la Educación, Santiago, Chile. (no prelo)

Internet :

http://www.snel.org.br/noticias/jornal30.htm

Acessado em em 02 de novembro de 2006. 